\title{
Sturge-Weber syndrome: Clinico-neuroradiological features and treatment profile
}

\author{
Anirban Chatterjee $M D^{1}$ iD, Malay Kumar Sinha $M D^{2}$ iD \\ ${ }^{1}$ Pediatric Medicine, Maharaja Jitendra Narayan Medical College and Hospital, Coochbehar, West Bengal, India \\ ${ }^{2}$ Pediatric Medicine, Institute of Post Graduate Medical Education and Research, Kolkata, West Bengal, India
}

Date of submission: $15^{\text {th }}$ February 2021

Date of acceptance: $19^{\text {th }}$ July 2021

Date of publication: $1^{\text {st }}$ September 2021

\section{Abstract}

Introduction: Sturge-Weber syndrome (SWS) is a rare, nonhereditary genetic disorder. SWS belongs to a diverse group of neurocutaneous disorders. A somatic mutation in the early development of cells in SWS patients causes the formation of a congenital capillary vascular malformation. SWS is characterized by nevus flammeus on the face (also called Port-Wine Birthmark), brain (leptomeningeal angioma), and eyes (glaucoma).

Methods and Materials: We present three patients diagnosed with Sturge-Weber syndrome who attended a teaching hospital between 2013 to 2016 . The clinical, neuroradiological features and treatment of SWS patients were reviewed retrospectively from medical records.

Results: Two males and one female with SWS were reviewed. The facial nevus flammeus was unilateral in one patient and bilateral in two patients. The extensive nevus flammeus including the face, trunk, and upper limb was found in one patient. Epilepsy, neurodevelopmental delay, and intellectual disability were the most common presentation in the series. Episodic hemiparesis was manifested in one patient. Levetiracetam and oxcarbazepine, either single or combined, were used in every SWS patient $(n=3)$. Six months seizure-free was obtained in a patient with SWS with combined anticonvulsant therapy.

Conclusion: Drug-refractory and early-age epilepsy is associated with lower intelligence level that consequently affects poor social skill and quality of life in the patients with SWS. Sudden or gradual loss of vision is also a threat for SWS patients. Diagnosis at birth or during early age, multidisciplinary intervention, and follow-up is a must to improve absolute outcomes in the patients with SWS.

Key words: Anticonvulsant, CT, Epilepsy, MRI, Nevus flammeus, Sturge-Weber syndrome.

\section{Introduction}

$\mathrm{N}$ Teurocutaneous disorder (NCS) is a diverse group of congenital disorders involving the skin, nervous system, and other organs. NCS is considered a

Access this article online
Website: https://www.nepjol.info/index.php/NJN
DOI: https://doi.org/10.3126/njn.v18i3.34969
HOW TO CITE
Chatterjee A, Sinha MK. Sturge-Weber syndrome: Clinico-
neuroradiological features and treatment profile. NJNS.
2021;18(3):49-54.

Address for correspondence:

Dr. Anirban Chatterjee

Maharaja Jitendra Narayan Medical College and Hospital,

Coochbehar, West Bengal, India.

E-mail:dr28ac@gmail.com

Phone: +91 6290686272

Copyright (C 2021 Nepalese Society of Neurosurgeons (NESON)

ISSN: 1813-1948 (Print), 1813-1956 (Online)

This work is licensed under a Creative Commons Attribution-Non Commercial 4.0 International License. differentiation defect during the development of primary neuroectoderm and sometimes mesoderm. ${ }^{1}$ The etiology of NCS is gene changes. The three most common neurocutaneous syndromes are tuberous sclerosis, neurofibromatosis, and Sturge-Weber syndrome (SWS).

There is a developmental defect of the vascular system in an embryonic stage in patients with SWS. In this anomaly, a plexus of the vascular system fails to regress at the cephalic part of the neural tube that forms facial skin. These persistent vascular tissues create abnormal development as well as the growth of vascular structures. ${ }^{1}$ These abnormal blood vessels are characteristically capillary vascular malformations which are also found in different organs in the patients with SWS. ${ }^{2}$

Stasis of blood flow in the malformed vessels causes ischemia that results in cortical necrosis, atrophy, and subsequent deposition of calcification under the angioma. ${ }^{2}$

There is no published literature available, mentioning a consensus diagnostic criteria for SWS laid by a scientific body. Bachur CD et al. ${ }^{3}$ mentioned that SWS is diagnosed if two out of three diagnostic criteria are present: nevus flammeus (port-wine birthmark) on the face, leptomeningeal angiomatosis and glaucoma. 


\section{Chatterjee et al}

The diagnosis should be suspected either at the time of birth or as early as possible. Port-wine birthmarks (PWB) are present at the time of birth. Bilateral PWB predicts a higher probability for epilepsy. ${ }^{4}$ In presence of PWB or suspicion of SWS, developmental venous anomaly (DVA) in the brain must be looked for by neuroimaging as the presence of DVA indicates an increased probability for epilepsy. ${ }^{4}$ DVA is manifested with epilepsy in $73 \%$ and without epilepsy in 23\%. ${ }^{4}$ Bilateral nevus flammeus and DVA have a $100 \%$ possibility of epilepsy. ${ }^{4}$

We review the clinical-neuroradiological features and management of three patients with SWS and discuss relevant literature on SWS.

\section{Methods and Materials}

This is a case series of three Sturge-Weber Syndrome patients. SWS was diagnosed by the presence of two diagnostic criteria of three. These SWS patients have attended a teaching hospital in Eastern India from 2013 to 2016. The clinical, neuroradiological features and treatment of the three SWS patients were reviewed retrospectively from medical records. This study was exempted from ethical committee approval as it was a retrospective observational case study.

\section{Results}

The clinical details of the patients with SWS are presented in Table 1.

In the present series, all three patients were serially examined for glaucoma in the ophthalmology department; however, none was diagnosed with glaucoma.

In cases 2 and 3 , phenobarbitone was the initial antiepileptic $(5 \mathrm{mg} / \mathrm{kg} /$ day $)$ which was started before the age of one year. Then, levetiracetam was added as the seizure was uncontrolled. Levetiracetam was the initial agent $(10 \mathrm{mg} / \mathrm{kg} /$ day) for case 1 .

At the time of study, the anticonvulsant regimen of the eight-years old male (case 2) was oxcarbazepine, levetiracetam and valproate. The other two (cases 1 and 3) were receiving oxcarbazepine and levetiracetam. All were receiving low-dose aspirin during the study. $\mathbf{a}$

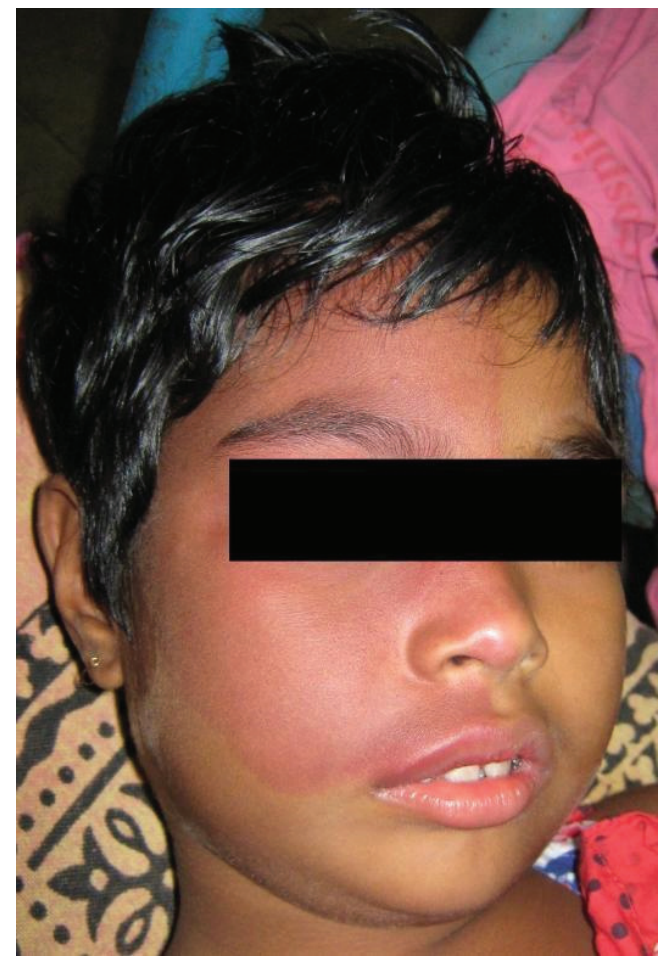

$\mathbf{b}$

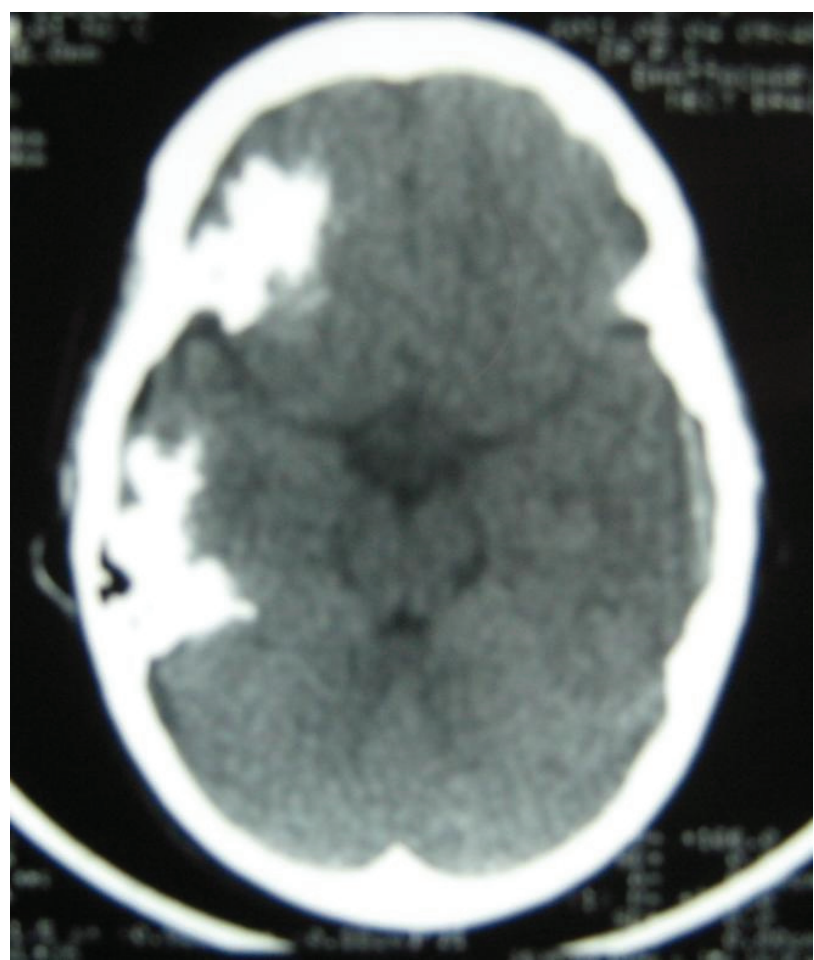

Figure 1a: Facial port-wine stain on right side trigeminal nerve V1 and V2 distribution.

1b: CT Brain displays gyriform calcification on the area of right fronto-temporal and occipital region. 

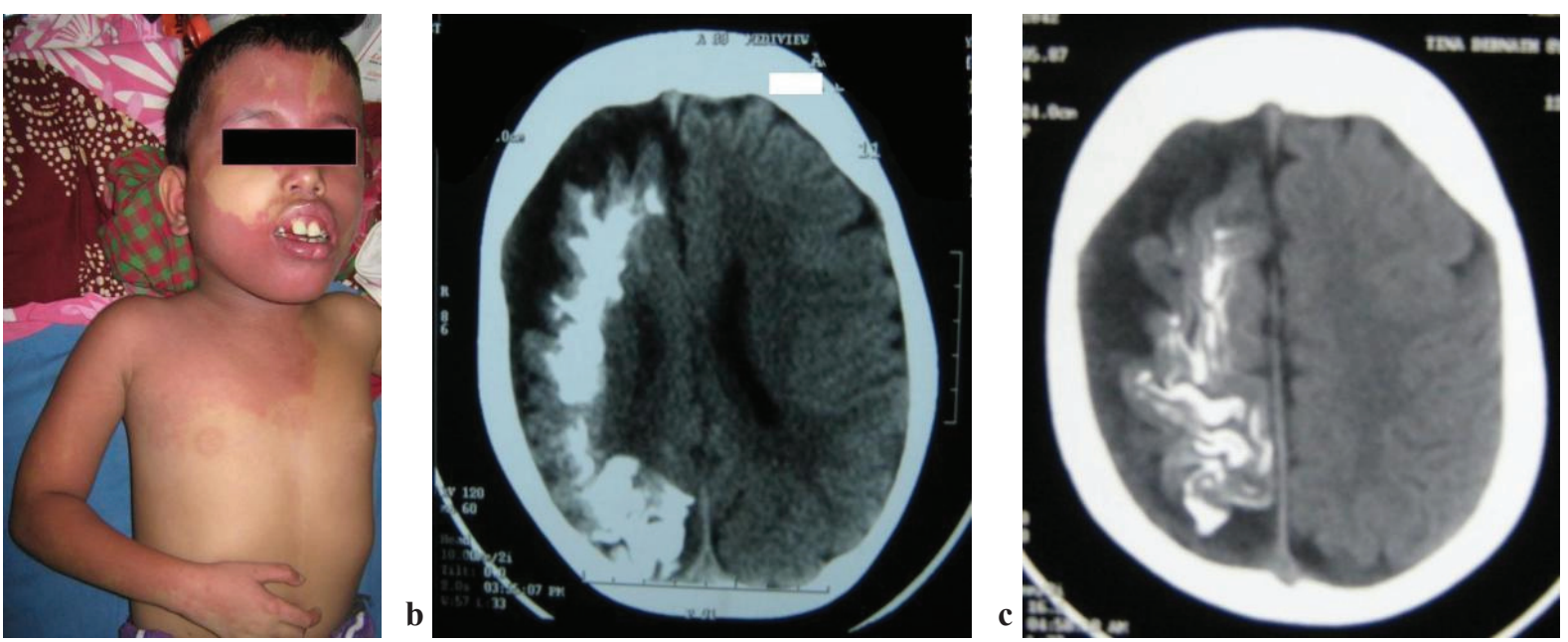

Figure 2a: Port-wine stain on both sides of face, right upper chest and right upper limb. 2b, 2c: CT shows a dense gyriform calcification on entire right hemisphere and cortical atrophy.
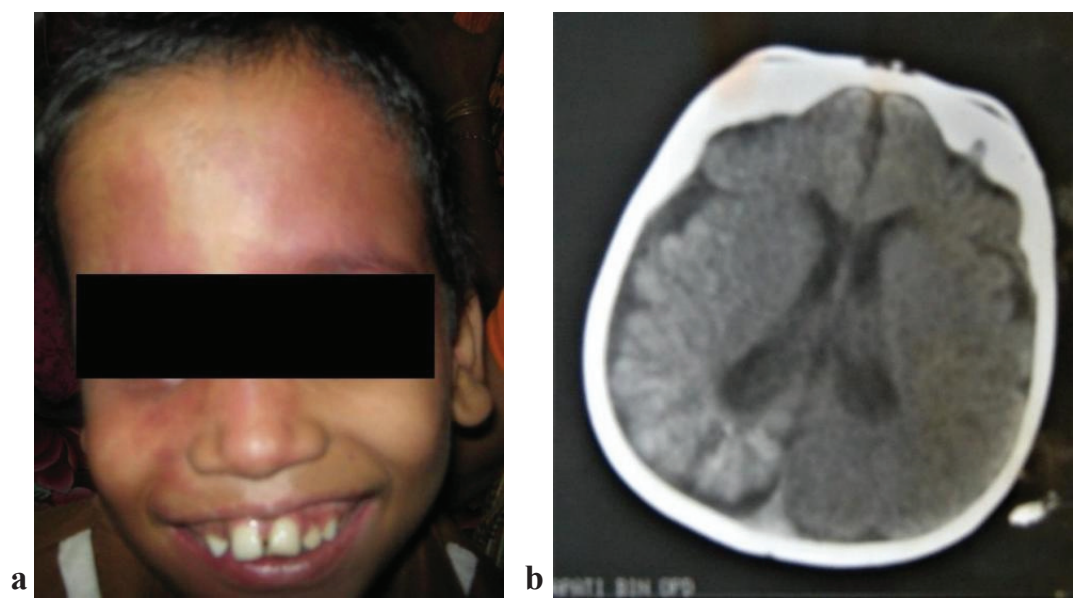

Figure 3a: Port-wine birthmark found on both sides of face. 3b: CT scan shows a gyriform calcification on the occipitotemporal region.

\begin{tabular}{|c|c|c|c|c|c|}
\hline Case & $\overline{\text { Age }}$ & Gender & Skin lesions & Neurological manifestations & Neuro-radiological finding \\
\hline 1 & 6 year & Female & $\begin{array}{l}\text { nevus flammeus } \\
\text { (port-wine } \\
\text { birthmark) in } \\
\text { unilateral (Right) } \\
\text { Face (Figure 1a) }\end{array}$ & $\begin{array}{l}\text { Epilepsy (seizure started } \\
14 \text { months of age, Status } \\
\text { epilepticus } \\
\text { Neurodevelopmental delay } \\
\text { Mental retardation }\end{array}$ & $\begin{array}{l}\text { Gyriform calcification subcortical white } \\
\text { matter noted in right frontal temporal } \\
\text { and occipital region with evidence } \\
\text { of prominent subcortical medullary } \\
\text { and subependymal veins and cortical } \\
\text { atrophy in the same region (Figure } 1 \mathrm{~b} \text { ) }\end{array}$ \\
\hline 2 & 8 year & Male & $\begin{array}{l}\text { nevus flammeus } \\
\text { bilateral face, } \\
\text { Right upper chest, } \\
\text { right upper limb } \\
\text { (Figure 2a) }\end{array}$ & $\begin{array}{l}\text { Epilepsy (Seizure started } \\
\text { at age of eight months } \\
\text { status epilepticus, cluster } \\
\text { convulsion), Mental } \\
\text { retardation/intellectual } \\
\text { disability gingival hyperplasia. }\end{array}$ & $\begin{array}{l}\text { Gyriform calcification at right fronto- } \\
\text { parieto-occipital region and right } \\
\text { hemisphere atrophy (Figure } 2 \mathrm{~b}, \mathrm{c} \text { ) }\end{array}$ \\
\hline 3 & 4 year & Male & $\begin{array}{l}\text { nevus flammeus } \\
\text { on bilateral Face } \\
\text { (Figure 3a) }\end{array}$ & $\begin{array}{l}\text { Epilepsy (Seizure started at } \\
\text { age of five months, status } \\
\text { epilepticus, cluster convulsion) } \\
\text { mental retardation/ intellectual } \\
\text { disability transient episodic } \\
\text { hemiparesis }\end{array}$ & $\begin{array}{l}\text { Gyriform calcification right hemisphere } \\
\text { and atrophy (Figure 3b) }\end{array}$ \\
\hline
\end{tabular}

Table 1: Description of clinical findings and neuroimaging 


\section{Chatterjee et al}

\section{Discussion}

Sturge-Weber syndrome (SWS) is a rare $^{3}$ and only non-hereditary neurocutaneous syndrome. ${ }^{1} \mathrm{SWS}$ is caused by the mosaic pattern of a somatic mutation at the GNAQ gene (sited on chromosome 9q21). This somatic mutation occurs in the early phase of development of a cell after conception, so the mutant gene is non-inherited. ${ }^{2}$

The exact incidence of SWS has not been studied in the literature. ${ }^{6}$ The frequency of SWS is estimated to be 1 in 2000 to 1 in $50,000 .^{2}$ In a recent population-based study, Rihani et al showed that the incidence rate of patients with SWS was $0.19 / 100,000 /$ year with a female predominance $(69 \%)$ [male (31\%)]. ${ }^{6}$ In the present series, two males and one female with SWS were studied. The family history of SWS or any genetic disease in the family was not reported in our series.

Port-wine birthmark (PWB) presents as a flat, blanchable, pink to red color patch on the skin, anywhere in the body. ${ }^{2} \mathrm{PWB}$ is a congenital capillary malformation in the skin. ${ }^{2} \mathrm{~A}$ PWB is the most specific marker of SWS since birth, and persists for lifelong in SWS. ${ }^{2}$ PWB appears typically unilaterally, on the right side of the face in $87 \%$ to $90 \%$ of patients with SWS and $30 \%$ bilateral presentation. ${ }^{7}$ This may be extensive involving bilateral face $^{8}$ and may extend to the trunk and limbs. In the present series, one patient (case 1) had unilateral right-side face involvement. Two (cases 2 and 3) had bilateral facial lesions. Also, one patient (case 2) had an extended lesion affecting the trunk and right upper limb.

It has been seen that bilateral or extensive nevus flammeus has no relation with seizure disorder. ${ }^{8}$ In our series, both Unilateral and bilateral cases had seizure disorder. Furthermore, the seizure-free period is lower (less than three months) in the patients with both side lesions (cases 2 and 3) compared to unilateral facial nevus flammeus (case 1). The bilateral facial involvement predicts a higher possibility of seizure disorder. ${ }^{9}$

Parents complained that the color of the nevus flammeus became deeper (deep red to purple) during seizures. Also, similar findings were reported by other authors. $^{2}$

Primary central nervous system presentations of SWS are epilepsy, hemiparesis, cognitive impairments and visual field defects. Epilepsy is the most common neurological presentation in SWS. Convulsions have been present in $75 \%$ to $90 \%{ }^{5}$ of patients with SWS. Seizures have been reported in $73 \%$ of patients with unilateral leptomeningeal involvement and $93 \%$ of patients with bilateral affection. ${ }^{5}$ Status epilepticus is the most frequent cause of multiple times hospital admission.

In the series, the patients with SWS (cases 1, 2 and 3 ) had generalized tonic-clonic seizures. In two (cases 1 and 2) seizures had started before one year of age with the first presentation being a focal seizure. Two patients (cases 2 and 3) had experienced cluster convulsion which is a repeated short duration convulsion in a day. Earlier studies had made similar observations. ${ }^{2,5,10}$ Focal seizure have been reported in $45 \%$ of SWS patients in the initial phase and generalized tonic-clonic being the most common type of convulsions. ${ }^{5,10}$

The first convulsion has been recorded before age of one year in $75 \%$ of patients with SWS. ${ }^{11}$ The range of onset is from birth to six years (mean eight months). ${ }^{12}$ In some cases, convulsion may not present until adulthood (third decade). ${ }^{11}$ Furthermore, the cluster seizures have been seen in $45 \%$ of the patients with SWS. ${ }^{12}$

Electroencephalogram (EEG) changes over time. EEG changes were non-specific in the present series.

The brain affection in the patients with SWS is diagnosed by enhancing leptomeningeal angioma after one year. ${ }^{13}$ The contrast-T1 MRI may not able to detect the leptomeningeal angioma in the first year. ${ }^{4}$ However, the CT scan delineates the cortical calcification in SWS early, so $\mathrm{CT}$ is considered as the better diagnostic procedure in the first year of age when compared to MRI. ${ }^{5}$

Contrast-enhanced MRI is the standard diagnostic choice for visualizing leptomeningeal angioma after the age of one year. ${ }^{4}$ However, MRI may fail to detect cortical dysplasia which is sometimes associated with a patient with SWS. ${ }^{4}$ In the present series, CT/ MRI documented leptomeningeal angioma in all the three cases. In addition, two patients had cortical atrophy and cortical-subcortical calcification.

Oxcarbazepine/carbamazepine and levetiracetam are the most commonly employed anticonvulsant in SWS patients. ${ }^{14}$ Oxcarbazepine/carbamazepine or levetiracetam is commonly used as a first-line either as monotherapy or in combination. ${ }^{14}$ It is observed that oxcarbazepine/ carbamazepine is better anticonvulsant than levetiracetam in terms of seizure-control in the SWS cohort. ${ }^{14}$

Oxcarbazepine, levetiracetam and phenobarbital are the most common anticonvulsant used for treatment in infants. ${ }^{13}$ In addition, levetiracetam and valproate are commonly used anticonvulsant to treat patients with both focal and generalized convulsions.${ }^{13}$ and oxcarbazepine / carbamazepine for focal seizures alone. Also, Phenobarbitone controls seizure in a few cases of SWS. ${ }^{14}$ Polypharmacy (two or more than two) has been more commonly advocated to manage uncontrolled seizures. ${ }^{14}$ In the present series, all three patients were taking two or three anticonvulsants at the time of the study.

Aggressive antiepileptic therapy is advisable to prevent stroke and cortical damage ${ }^{13}$ which may cause further intellectual disability. Drug-resistant epilepsy may require surgical lobectomy to control seizure. ${ }^{12}$ However intellectual deficits and hemiparesis do not improve satisfactorily after surgery. ${ }^{12}$ 
After a decade of review on the patients with SWS, Lance EI et $\mathrm{al}^{15}$ documented that low-dose aspirin (3-5 $\mathrm{mg} / \mathrm{kg} /$ day) has significantly improved the spectrum of neurodevelopmental outcome in patients with SWS. Aspirin reduces the severity and frequency of convulsions, transient hemiparesis, and the higher score of cognitive function, etc. without any significant side effects. ${ }^{15}$ Aspirin is a safe drug even in below one month of birth. ${ }^{15}$

Ocular involvement has been reported in $30 \%$ of patients with SWS. ${ }^{5}$ Abnormal vascular malformations have been seen in various sites in the eye and ipsilateral to a facial PWB. ${ }^{6}$

Glaucoma is the most frequent ocular manifestation reported in the literature $\left(30 \%{ }^{5}\right.$ to $\left.74.5 \%^{12}\right)$ and develops from birth to adulthood (40\%). ${ }^{3}$

A diffuse choroidal hemangioma is seen as $33 \%$ SWS and causes vision loss. ${ }^{2}$ The other common ocular conditions are dilated episcleral vessels, buphthalmos, megalocornea and retinal detachment. ${ }^{6}$

Intellectual disability (50\%), and hemiparesis (30\%) commonly occur as neurological complications of SWS. ${ }^{5}$ In the present series, all SWS $(n=3)$ have been suffering from mental retardation. Patients have gross delayed development in four domains and intellectual ability was poor compared to peers. Wechsler Intelligence Scale for Children (WISC) could not be done. Bilateral involvement, early onset of a seizure and refractory epilepsy are the poor prognostic factors for intellectual disability and severe loss of motor function. ${ }^{12}$

In the present series, one patient had multiple episodes of transient hemiparesis which recovered every time spontaneously within three days. The recovery timeframe of transient episodes to revert back to previous condition is 1 minute to 4392 hours (median 24 hours) ${ }^{16}$ and associated factors are seizure or following a hit on the head. ${ }^{16} 46 \%$ with SWS suffered from permanent hemiparesis. ${ }^{16}$

\section{Conclusion}

SWS is a rare, non-hereditary disorder with multisystem involvement of developmentally malformed capillaries. Bilaterally extensive port-wine birthmarks predict severe early-onset epilepsy. Epilepsy is the most common neurological presentation; frequently before one year. CT (below one year of age) or MRI (above one year of age) is the recommended neuroimaging study to diagnose leptomeningeal angioma. Oxcarbazepine and levetiracetam, either alone or in combination, are the most frequently used anticonvulsants. Low-dose aspirin reduces the frequency and severity of epilepsy as well as hemiparesis. The serial ocular examination from birth is important for early diagnosis of eye involvement to prevent vision loss.
Early diagnosis, multidisciplinary intervention, and continuous follow-up must be advocated.

Acknowledgement: We are thankful to the patient and their families for giving us consent to publish these cases.

\section{Conflict of Interest: None \\ Source(s) of support: None}

\section{References}

1. Klar N, Cohen B, Lin DDM. Neurocutaneous syndromes. Handb Clin Neurol. 2016;135:565-89. https://doi.org/10.1016/B978-0-444-53485-9.000271

2. Sturge-Weber syndrome. Genetics Home Reference [Internet] Bethesda: U.S. National Library of Medicine.; c2018-10[updated 2020-08]; https:// ghr.nlm.nih.gov/condition/sturge-weber-syndrome [Accessed 2021-02]

3. Bachur CD, Comi AM. Sturge-weber syndrome. Curr Treat Options Neurol. 2013;15(5):607-17. https:// doi.org/10.1007/s11940-013-0253-6

4. Kaseka ML, Bitton JY, Décarie JC, Major P. Predictive factors for epilepsy in pediatric patients with SturgeWeber Syndrome. Pediatr Neurol. 2016;64:52-8. https://doi.org/10.1016/j.pediatrneurol.2016.08.009

5. Neto FX, Junior MA, Ximenes LS, Jacob CC, Junior AG, Palheta CP. Clinical features of SturgeWeber syndrome. Intl Arch Otorhinolaryngol. 2008;12(4):565-70. http://www.arquivosdeorl.org. br/conteudo/acervo eng.asp? $\mathrm{Id}=573$

6. Rihani HT, Dalvin LA, Hodge DO, Pulido JS. Incidence of Sturge-Weber syndrome and associated ocular involvement in Olmsted County, Minnesota, United States. Ophthalmic Genet. 2020;41(2):10824. https://doi.org/10.1080/13816810.2020.1731834

7. Inan C, Marcus J. Sturge-Weber syndrome: Report of an unusual cutaneous distribution. Brain Dev. 1999;21(1):68-70. https://doi.org/10.1016/s03877604(98)00067-9

8. Uram M, Zubillaga C. The cutaneous manifestations of Sturge-Weber syndrome. J Clin Neuroophthalmol. 1982;2(4):245-8. PMID: 6226707.

9. Tallman B, Tan OT, Morelli JG, Piepenbrink J, Stafford TJ, Trainor S, et al. Location of port-wine stains and the likelihood of ophthalmic and/or central nervous system complications. Pediatrics. 1991;87(3):323-7. PMID: 1805804.

10. Di Rocco C, Tamburrini G. Sturge-Weber syndrome. Childs Nerv Syst. 2006; 22: 909-21. https://doi. org/10.1007/s00381-006-0143-2 


\section{Chatterjee et al}

11. Sujansky E, Conradi S. Outcome of SturgeWeber syndrome in 52 adults. Am J Med Genet. 1995;57(1):35-45. https://doi.org/10.1002/ ajmg. 1320570110

12. Pascual-Castroviejo I, Pascual-Pascual SI, VelazquezFragua R, Viaño J. Sturge-Weber syndrome: Study of 55 patients. Can J Neurol Sci. 2008;35(3):301-7. https://doi.org/10.1017/s0317167100008878

13. Comi A. Current therapeutic options in Sturge-Weber Syndrome. Semin Pediatr Neurol. 2015;22(4):295301. https://doi.org/10.1016/j.spen.2015.10.005

14. Kaplan EH, Kossoff EH, Bachur CD, Gholston M, Hahn J, Widlus M, et al. Anticonvulsant efficacy in Sturge-Weber Syndrome. Pediatr Neurol. 2016;58:31-6. https://doi.org/10.1016/j. pediatrneurol.2015.10.015

15. Lance EI, Sreenivasan AK, Zabel TA, Kossoff EH, Comi AM. Aspirin use in Sturge-Weber syndrome: Side effects and clinical outcomes. J Child Neurol. 2013;28(2):213-8. https://doi. org/10.1177/0883073812463607

16. Tillmann RP, Ray K, Aylett SE. Transient episodes of hemiparesis in Sturge Weber Syndrome Causes, incidence and recovery. Eur J Paediatr Neurol. 2020;25:90-6. https://doi.org/10.1016/j. ejpn.2019.11.001 